\title{
A Social Inquiry Analysis of Post-Pandemic Higher Education: A Futures Perspective
}

\author{
M. Jayne Fleener \\ North Carolina State University
}

This paper explores higher education futures post the Corona virus pandemic. It uses futures and social inquiry approaches to explore how post-pandemic times will impact higher education. As a research method, social inquiry connects across social systems to explore complex relationships and impacts, providing a broader perspective of potential influences and synergies of social phenomenon. Social inquiry research shifts focus away from causal affects to explore patterns of connectivity and is therefore an appropriate methodology for futures inquiry. An examination of 141 trends associated with COVID-19 impacts provided the data for futures analyses through a Causal Layered Analysis approach. Three guiding questions including how we can address the challenges and embrace the opportunities of post-pandemic times to create more equitable, inclusive and sustainable higher education futures were explored. Results point to the need to rethink our social metaphors for more equitable and desirable higher education futures. Implications of this research suggest the need to examine and revision the purpose and values of higher education to meet the needs of individuals and society.

Keywords: futures, social inquiry, higher education, post-pandemic times, metaphors

\section{BACKGROUND: POST-PANDEMIC TIMES (PPT)}

Post-pandemic times (PPT) conveys a period in time where society is accommodating challenges associated with the worldwide COVID-19 pandemic of 2020. While we are still in the process of recovery, and the pandemic is by no means completely behind us, dramatic social systems challenges have occurred as different countries engage various strategies for and represent varying stages of recovery.

PPT occurs in the middle of another societal revolution where social and technological changes are challenging all sectors of society. Sadar and Sweeney $(2016,2020)$ describe this current social context of unprecedented interconnectivity and accelerated social and technological change as Post-Normal Times (PNT). PNT extends the uncertainties represented in postnormal science (Funtowicz \& Ravetz, 1993) as indications of similar challenges to all of our social systems (CPNFS, 2021). PNT is different from other "post" movements such as postmodernism, post-structuralism, or post-colonialism. PNT does not represent a criticism or denial of some past movement, discipline, or intellectual discourse. PNT describes the societal context of disruptive forces across social systems indicating the need for radical social transformation and change to occur.

PNT are evident as doubts about our most basic facts and values are being called into question in all dimensions of society. We see many examples of living in PNT. From the perspective of what it means to be a patriotic citizen, we see how opposing sides have very different perceptions of the attacks on the US 
Capitol on January 6, 2021. Differing views of the "facts" in many police actions against minorities are called into question. Demonstrations associated with the Black Lives Matter movement in the US are deemed important to civil and social discourse, on the one hand, and vilified as excuses for rioting and destruction of civil society, on the other. Even our national news agencies are split about what "facts" are relevant, what they mean, and how we make sense of current events. The proliferation of conspiracy theories not only reflects the challenges of living in PNT and accommodating ambiguity and change, but further exacerbates what counts as facts and how "reality" is perceived, constructed, and used to further divide people on key issues. The acceleration of changes in technology and information is evident from the perspective of knowledge generation and expectations. While by some estimates, societal knowledge at the beginning of the modern era was doubling every 100-200 years, we now see a doubling of knowledge every 12 hours! (Schilling, 2013).

During PNT, society is confronted by the failure to have consequential, collaborative, shared conversations and compromises in handling human activity (Palese, 2013). PNT and rapid change at every dimension of society accelerate the need for individual and social transformation.

From a social systems perspective (Luhmann, 1990), PNT can be found in all social, technological, economic, environmental, political and artistic (STEEPA) dimensions of society. As we experience PNT across these social contexts, we undergo the same processes described by Thomas Kuhn in Structure of Scientific Revolutions (1962) where normal science can no longer continue in the face of incommensurable contradictions. All sectors of society are implored by existing in PNT to rethink how to accommodate these changes to survive in the future.

PPT is a specific time period of PNT brought on by the COVID-19 pandemic. While many of the challenges of PNT cannot be tied to one specific event or set of circumstances, the world-wide pandemic of 2020 can be identified as a turning point, wake-up call, indication, and/or symptom of the transitions that need to occur as we engage with PNT. While many could ignore PNT before the pandemic, most people understand that the world will not go back to how it was before the pandemic. So this slice in time offers an impetus and frame for discussing the future of higher education.

The figure below adapts what futurists call the Futures Cone (Bishop \& Hines, 2012) to show the relationship among PNT, the advent of COVID-19, and PPT as they impact our possible explorations of future possibilities. The Expanded Futures Cone (Fleener 2021), considers an "expanded now" as we reflect on and interrogate our current circumstances, often requiring a re-examination of the past. The expanded now engages inquiry to explore probable, plausible, possible and preferred futures (Dator, 2011) as well as entertain expanded possible futures (Fleener, 2021). Obviously, the future is unknown and especially during PNT, traditional predictive approaches are no longer valid. But through futuring activities (Hines et al., 2017) we can begin to explore and develop strategies for bringing about preferred and expanded possible futures. Aspirational futures (Bezold, 2020) go beyond exploration of possible futures as an abstract mental exercise ("futures for the head," p. 148) to engage communities in exploring preferred futures within the space of plausibility ("futures for the heart," p. 148). The process results in "visionary outcomes" as targets to shoot for. Thus, beyond developing plans based on foresight strategies as organizations might typically do during a strategic planning process, aspirational approaches incorporate vision, values, mission and goals for the changing futures. Aspirational futures is a systems approach that takes into consideration collective action and its impacts across social systems.

As seen in Figure 1, the COVID-19 worldwide pandemic was a major disruption to our trajectories into the future. With seeds already planted prior to 2020 both in terms of being in PNT and with the previous Zika outbreak in 2016, we can, in retrospect, see how our current trajectories into the future may impact the kinds of futures we need to create. Pre-COVID anticipations of the future may have predicted many of the possible challenges we will face in higher education in the next 30 years, but we now need to reassess and filter our expectations and visions of the future through the existing context of PPT.

This research will use futuring strategies (Bezold, 2020; Inayatullah, 2008; Hines et al., 2017; Slaughter, 2020) to explore possible and preferred futures of higher education. Within this context, we will create visions of preferred futures for higher education that may impact current actions and inform decision making conversations. 


\section{FIGURE 1 \\ FUTURES CONE FOR PPT FUTURES ANALYSIS}

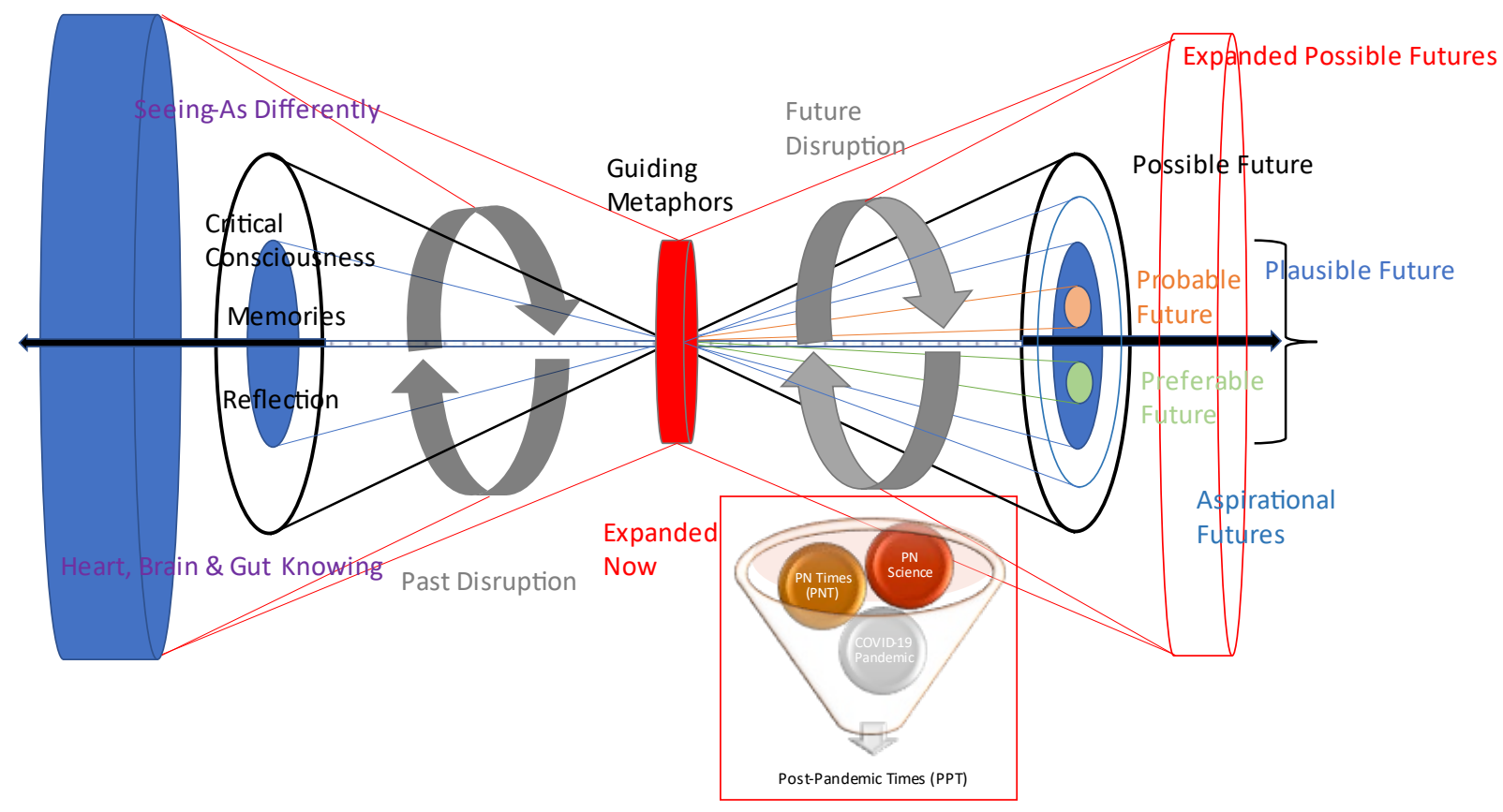

\section{INQUIRY PERSPECTIVES}

\section{Social Inquiry}

Social inquiry perspectives are used in this study to understand the impact of PNT and the need for addressing PPT challenges in higher education. Originating in anthropology, social inquiry recognizes the "conceptual need to link social behavior to wider social systems to meaningfully make interpretive sense of localized phenomena" (Greene, 2008, p.7). There is a recognition, from a social inquiry perspective, that human agency is just one avenue of impact on social, institutional, environmental and human relations. Human agency is neither privileged nor expected to have control over social systems but, rather, treats individual and collective action as part of an ecosystem of influences over social realities that include all of the STEEPA dimensions of a complex society. Social inquiry shifts focus from causality to patterns and relationships, recognizing the dynamics across social systems as comprising unique and unpredictable outcomes. Social inquiry suggests the need for a "research assemblage" to accommodate this complexity and address challenges across individual, social and environmental dimensions (Fox \& Alldred, 2015). Social inquiry is an especially appropriate approach to understand the ambiguity and uncertainty of the future and for addressing strategies for action that may support desirable possible and preferred futures within complex social settings.

Social inquiry assumes the social (ontological) world is connected to our epistemological understandings through our mental models, including values and beliefs, as processes and interactions (Fox $\&$ Alldred, 2015) and through our language and metaphors as implicit guides for social action (Inayatullah, 2008; Slaughter, 2020). As an inquiry approach, social inquiry "foregrounds an appreciation of just what it means to exist as a material individual with biological needs yet inhabiting a world of natural and artificial objects, well-honed micro-powers of governmentality, but no less compelling effects of international economic structures" (Coole \& Frost, 2010, p. 27). Social inquiry is an appropriate method for supporting research from a complex, social systems perspective (Dixon, 1984; Luhmann, 1990) and provides strategies for exploring how humans engage with and become a part of the productions of society (Greene, 2008). 
Social inquiry has used a range of research methodologies (Greene, 2006) and is not associated with any single empirical approach.

The focus of this study will be to engage a social inquiry perspective using futures approaches. While most research in some respects is backwards looking, engaging in "re-search" (Fleener, 2016) as a meaningmaking process, this study will use social inquiry from a futures perspective to explore the transformational needs of and transformative possibilities for higher education and will thus implement several futuring research strategies (Bezold, 2020; Hines et al., 2017; Inayatullah, 2008; Slaughter, 2020).

\section{Futuring Strategies}

As Figure 1 suggests, our anticipatory relationships with the future (Miller, 2018), include exploration of possible, plausible, probable and preferred futures (Bishop \& Hines, 2012). In research conducted by James Dator (2011), there are typically four perspectives of the future explored when people are asked to create scenarios about the future. These "archetypes" of visions of the future are summarized as growth, collapse, constraint and transformative perspectives of the future. Growth perspectives have an underlying logic of progress, prosperity, profit, and purpose. Collapse views of the future typically consider the consequences of unchecked growth as unsustainable and leading to collapse, demise or destruction. Constraint visions of the future describe ways to check unconstrained growth by incorporating new rules and regulations or appealing to the need for checks and balances, enforcement, and restraint. Constraint can also entail a return to some previous, past time, when growth was managed or in check.

These first three approaches to the future maintain existing structures or ways of doing things, even in the event of pending collapse. The underlying perspectives of the future maintained by these three approaches do not challenge basic understandings or underlying metaphors of how things are connected or supposed to be. Transformative futures approaches disrupt existing epistemological, ontological and ethical assumptions, explore new metaphors that guide how we look at the world, and create new ways of engaging and new cultural norms and myths. The social inquiry futures approach engaged in this study will focus on transformational futures opportunities. This means underlying assumptions and expectations for maintaining status quo of higher education will be called into question.

Sohail Inayatullah specifically developed strategies for critical futures approaches (Inayatullah, 1990) to expose social myths and metaphors that prevent transformative change from occurring and focus on underlying power relations. His Causal Layered Analysis (CLA) approach (Inayatullah, 2008) will be used for untangling social influences and dynamics occurring during PPT as we explore the future of higher education. Aspirational futures (Bezold, 2020) will be used within a CLA framework to maintain focus on social transformation that includes visioning for preferred social change.

\section{RESEARCH APPROACH}

\section{Data Sources}

Futures think-tank Avenear (nd) conducts strategic foresight studies for clients using trend analyses (Mendonça et al., 2004), strategic foresight (Hines \& Bishop, 2006) and design futures research (Candy \& Potter, 2019). Their COVID-19 Early Trends Report (Bugeaud, 2020) was published on April 26, 2020 and provided 141 future trends they identified through their strategic forecasting process. These 141 trends will serve as the primary data sources for this study.

\section{Analyses}

A Causal Layered Analysis (CLA) approach (Inayatullah, 2008) is used to examine the data generated by Bugeaud (2020) about post-pandemic trends. CLA has four layers of analysis that support deepening inquiry into future possibilities and preferred futures discussions. Litany is the first layer of analysis. During the Litany phase, the problem, its causes and relationships, and initial strategies are laid out. The Bugeaud 141 trends provide the data for the litany phase of the CLA.

As presented, the 141 trends are compiled and organized in social systems categories of impact: Social, Technological, Environmental, Economic, Political-Regulatory, Values and Arts and Culture 
(STEEPVAC). The 141 projections will be analyzed using content analysis (Neuendorf \& Kumar, 2016) to identify relational dynamics across STEEPVAC social dimensions. Since we are well into a post-pandemic era (PPT) a year after the publication and identification of the futures trends identified in the Bugeaud (2020) report, trends will be categorized within their STEEPVAC categories as temporary responses during the immediate aftermath of the outbreak, partially sustained trends that are likely to co-exist with past patterns of relationship, and longer-term trends that will replace, supplant, or challenge existing social structures and dynamics. For example, while mass graves was a temporary strategy early in the pandemic, working from home will likely be a trend that continues as an option in the future, so would be considered a partially implemented future trend. Values for work-life balance are trends that became apparent during the pandemic that will likely continue and so would be categorized as a longer-term trend. A visual representation of the trends will delineate insights about PPT during the Litany phase of analysis.

FIGURE 2

CAUSAL LAYERED ANALYSIS ANALYTIC FUTURING PROCESS

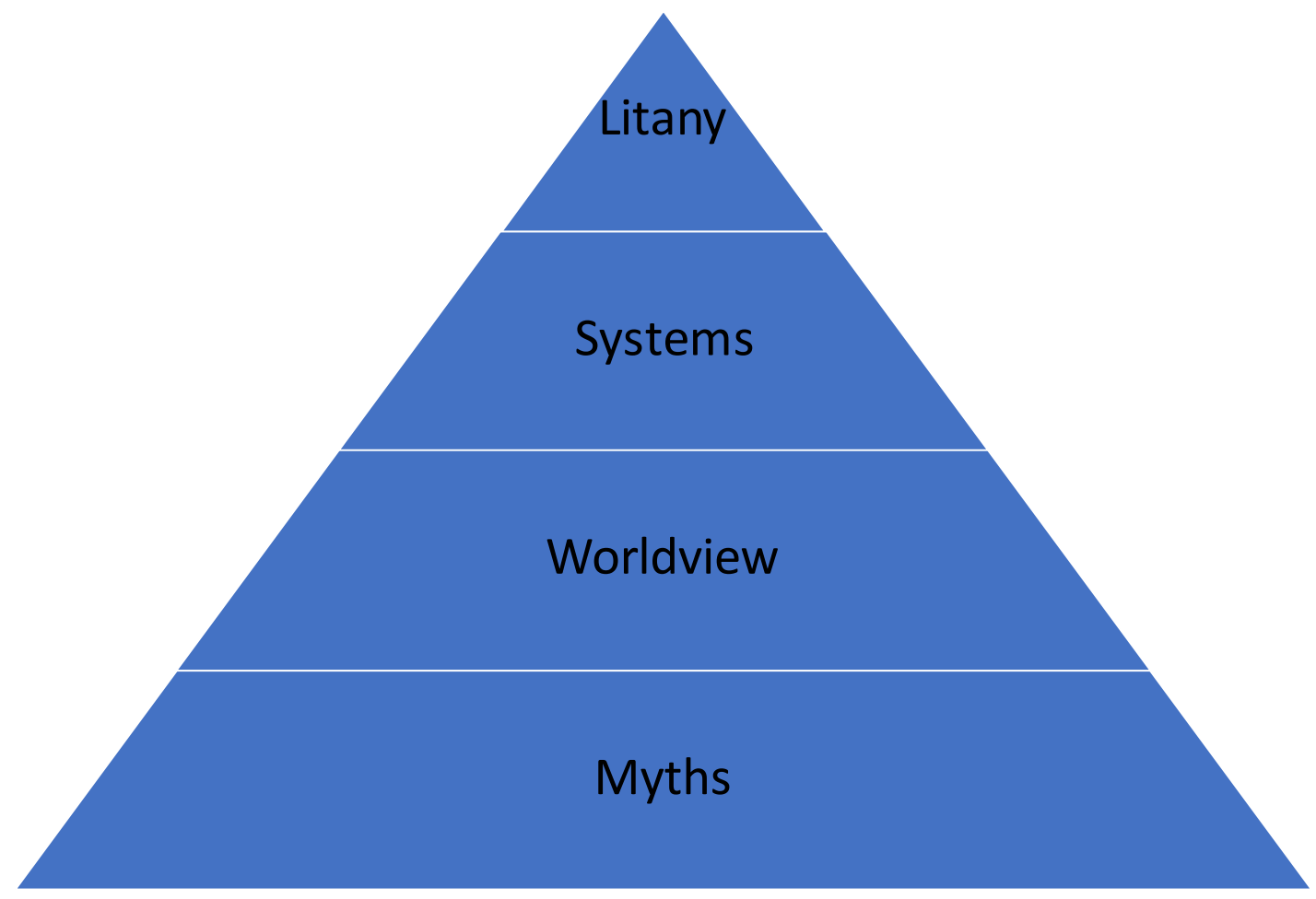

Inayatullah, 2008

Going deeper, beyond the listing of strategies and trends identified during the litany stage of the CLA, the second level of analysis explores System connections and relations, especially as they are related to the problem under investigation - in our case, the future of higher education. Causes, policies, histories, perspectives and social constraints will be explored at the systems level of analysis as they inform questions about the future of higher education. Each of the 141 futures trends is explored for its partial or sustained futures impact. Emergent categories of impact will frame a discussion of the possible futures emerging from the trends analyses from a systems-level perspective. The analysis of system connections across trends connects possible futures of higher education within the context of the STEEPVAC categories. Figure 3 shows the interrelationship among the social systems categories that will guide the systems-level analysis of the 141 trends. 


\section{FIGURE 3 \\ VENN DIAGRAM USED FOR CLA SYSTEMS ANALYSIS FROM A SOCIAL SYSTEMS FRAMEWORK}

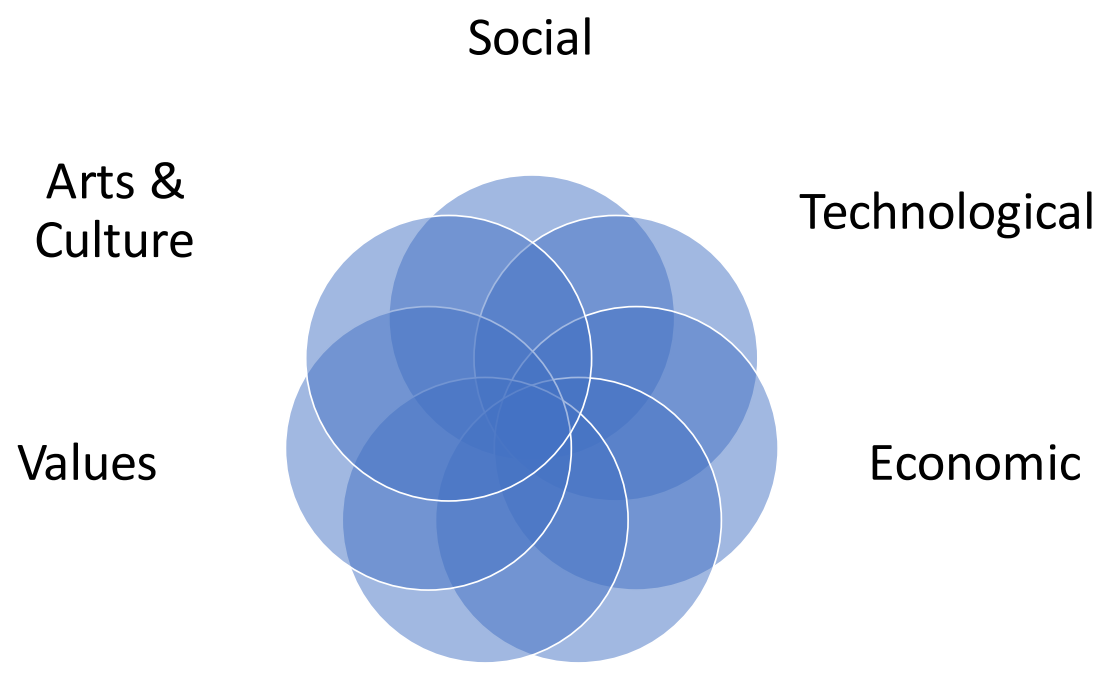

Political Environmental

The third level of CLA is Worldview. As a futuring strategy, the underlying worldview represented by strategies for the future both challenges and exposes existing world views and perspectives. Worldview analyses go beyond examination of survival and self-protection, challenging conventional perspectives and expectations, to explore deeper values across traditional social boundaries, disciplines and cultures (Slaughter, 2020). At this level of analysis, recommendations for higher education transformation as inferred in step two of the CLA are examined both for the worldview they convey and as a challenge to existing worldviews and perspectives across social systems dimensions. For the worldview analysis, the emergent categories of trends across STEEPVAC dimensions will be examined for their implied shifts and demands for social transformation. The worldview shifts indicate openings for changes in underlying myths, which the fourth level of the CLA analysis explores.

The fourth level of the CLA is to explore underlying social Myths and Metaphors. Uncovering the underlying myths of a society, the potential myths that emerge through the worldview analysis of higher education will be explored using an Integral Futures approach (Slaughter, 2020). Integral futures explore shifts and preferred futures from four different perspectives: individual-interior, individual-collective, social-interior, and social-collective. This approach to uncovering emerging and guiding myths as they impact the future of higher education is especially relevant to a social systems perspective with its integrated understanding of how individual and collective understandings interact with social and environmental dimensions. It is also a useful strategy for critical futures approaches as we end our inquiry with an appeal to preferred futures for social justice, shifting values and equity.

\section{Guiding Questions}

Guiding questions for this study are: (1) What are the long-term stressors to higher education resulting from the Coronavirus pandemic? (2) What are the possible, probable and preferrable futures for higher education? and (3) How can we address the challenges and embrace the opportunities of post-pandemic times to create more equitable, inclusive and sustainable higher educational futures? Results of these analyses will point to the need to rethink higher education, adult education, and our educational futures.

The first question will be answered through the level 1 Litany examination of the trends generated by Bugeaud (2020). The second question will be addressed through the level 2 Systems analysis, examining 
commonalities across STEEPVAC categories. The third question will be addressed through combining CLA level 3 and level 4 analyses (Inayatullah, 2008) with an Integral Futures approach (Slaughter, 2020) to generate new underlying myths and shifting worldviews required for transforming society. Below is a representation of the research processes and underlying perspectives framing this research.

\section{FIGURE 4 \\ EMBEDDED SOCIAL INQUIRY APPROACH TO THIS RESEARCH}

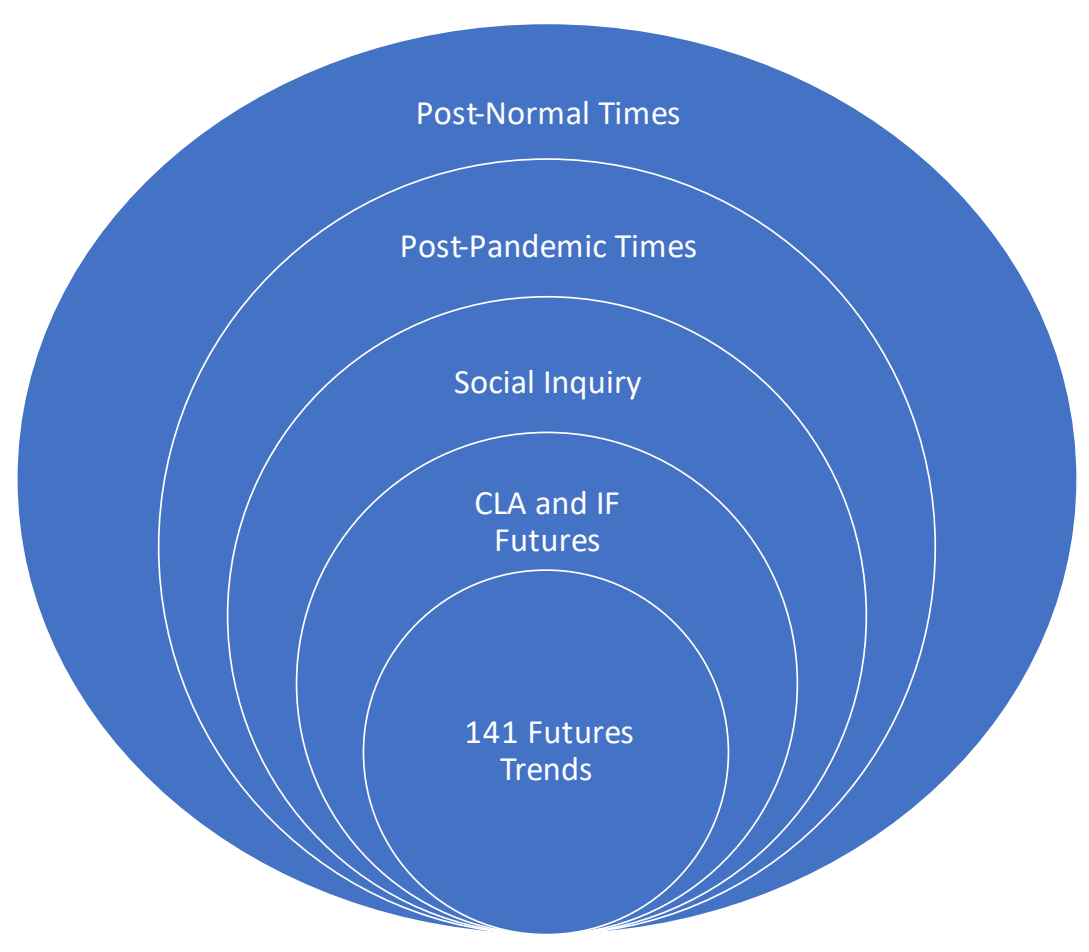

\section{FINDINGS}

The findings of this social inquiry analysis will be presented by their CLA categories of analysis.

\section{Litany}

The 141 trends compiled by the Bugeaud study (2020) served as the primary data for the social inquiry process into examining the possible, probable and preferred futures of higher education. Using content analysis (Neuendorf \& Kumar, 2016), each trend was first evaluated for temporary, short- or long-term potential impact. Temporary impacts were trends that were occurring early in the pandemic, at the time of the release of the Bugeaud study, that were no longer factors a year later. These kinds of trends included mass graves, personal protection equipment shortages, hording and mandatory quarantining for nursing homes and those returning from abroad. These trends were not used in the litany analysis of trends occurring during PPT.

Trends that are somewhat more permanent but may coexist with a return to how things were before the pandemic were categorized as Partial futures trends. Some examples of these trends include social distancing regulations, virtual entertainment, and restructuring of public spaces. While, for example, entertainment venues are beginning to open up, the technologies and strategies used for virtual entertainment during the pandemic lock-down will likely continue to be options. Longer-term trends that are likely to be sustained and potentially supplant traditional ways of doing things include trends such as increased use of virtual meetings, more work-at-home options, and changes to public transportation. 
Once the 141 trends were classified within their STEEPVAC categories, constructed categories were developed to understand commonalities across categories. These constructed categories will be especially useful in the Systems-level analysis and in discussing impacts on higher education as research questions are addressed later in the paper. Figure 5 below shows the delineation of these trends by numerical placement in the original list of 141 trends. Items in red indicated negative trends such as increased online pornography and internet scams due to increased use of virtual communications.

\section{FIGURE 5 STEEPVAC POST-PANDEMIC TRENDS SUMMARY}

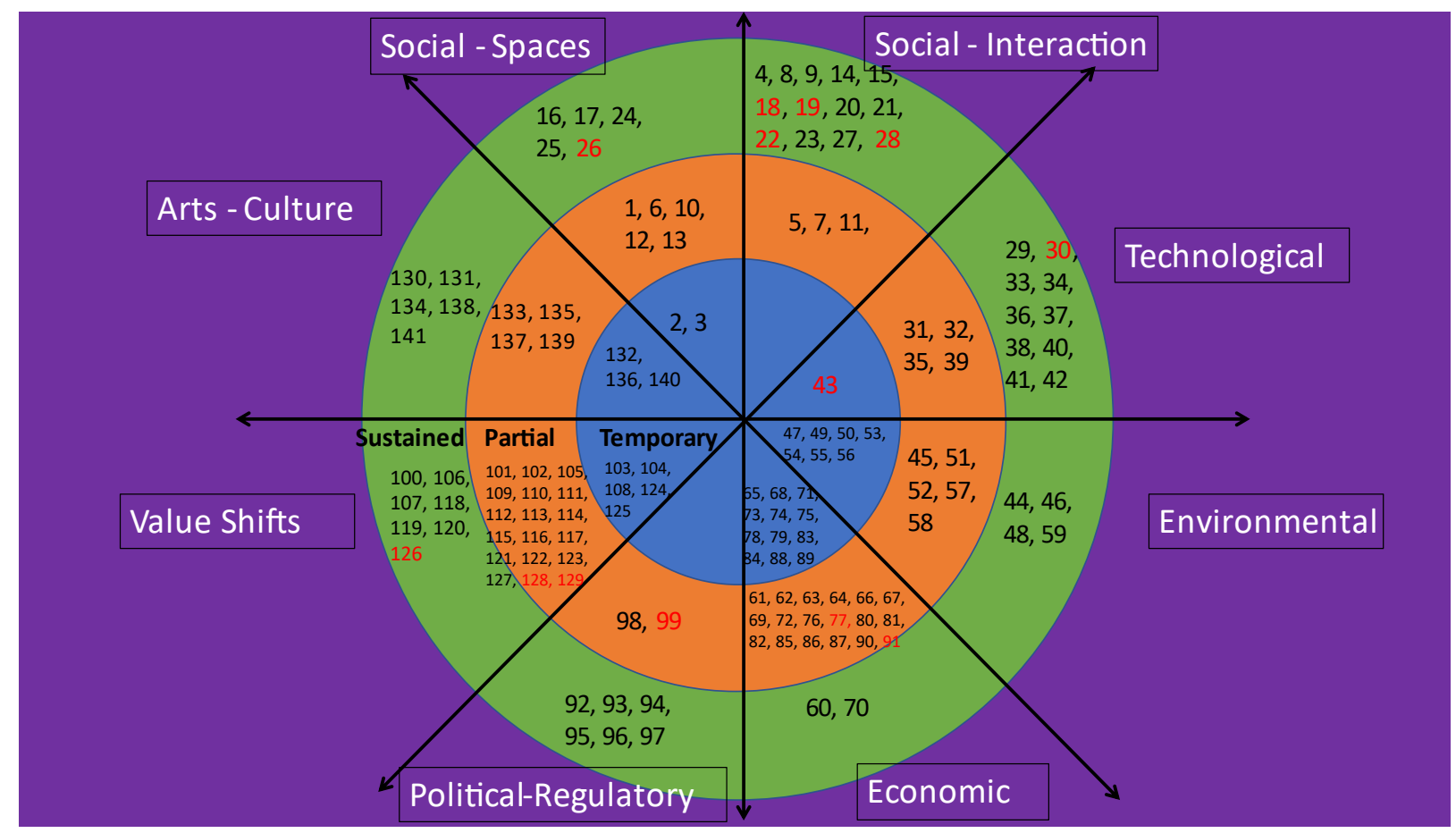

Trends in the social category were separated into social-spaces and social-interactions dimensions. After summarizing the 141 trends into temporary, partial and sustained categories, summaries of trends were examined using content analyses. The categorical summaries of trends are presented below.

\section{Social Stressors}

Impacts on social spaces and gatherings included challenges and stressors to how we interact and, while technology is listed as a separate social system impacted by the pandemic, within the social systems perspective, technological changes represented and supported both shorter-term and longer term social impacts. For example, shorter-term impacts included developing new ways for entertaining including livestreaming events, open sourcing and knowledge sharing. While large venues were closed during the pandemic, including theaters, sports arenas, and entertainment sites, there is some expectation that even as these venues begin to open, safety concerns as well as new ways of delivering entertainment developed during the pandemic will likely prevent full scale come back of in-person gatherings with expectations for parallel systems (Smyre \& Richardson, 2016) to accommodate safety concerns and increased expectations for bringing sports and entertainment into our homes.

The learning demands evident in the social categories included different learning modalities for formal (schooling), informal (job embedded), and non-formal (DIY, hobbies) learning. Associated with the increased learning demands resulting primarily from increased online presence were both increased socializing and entertainment options via technology as well as increased loneliness from separation. There 
were also social challenges associated with fear of the social environment pointing to increased concerns for physical safety and recognition of "bad players" who were taking advantage of increased dependence on technology for social outlets to plant seeds of chaos, disorder, mistrust and divisiveness or for personal gain.

\section{Technological \& Economic Stressors}

Technological and economic stressors listed in the 141 impacts of COVID-19 from the Bugeaud study represented both optimistic and dystopian views. Although listed in separate categories of impact, these two social systems structures will be summarized together because of the overlap of implied stressors.

For example, the use of technology for digital healthcare options as well as home delivery of medicine and other personal necessities represented positive, long-term impacts of technology to change the face of healthcare, products distribution, and commerce. Safety concerns were addressed by touchless consumer services that included new technologies to support purchasing and increase digital security for commerce. Technology supported commerce also saw a rise in online purchasing and a decrease in "aimless" shopping. Consumer fraud was included as a concern with increased technology use as it impacted online purchasing and the delivery and sales of products.

Increased connectivity was understood as both an opportunity for new forms of entertainment and learning but also as a potential equity concern. Implications of many of the items represented by the technology and economic shifts included long-term impacts on the economy for shifting values for worklife balance, flexible work schedules, and reconsideration of physical workspaces and facilities needs for businesses. Short term disruptions in the supply chain would have potential longer-term impacts on reducing dependency on international supplies and increasing local production, replacing large-scale production strategies with more localized and self-sustaining production approaches. Universal Basic Income, debt consolidation, and support for those severely impacted by the pandemic were categorized as both partial and sustained strategies for longer-term changes for their potential impact on economic structures and supporting individuals for their contributions to society beyond traditional pay-for-work strategies. Technological support for rapid prototyping for immediate needs as well as for creating longterm solutions to creating and distributing new products also was considered for its potential long-term changes to economic structures. And the increased use of robots for manufacturing, delivery and home services was considered a stressor introduced by need during the pandemic that will likely continue in the longer-term.

Virtual reality was also explored as important to both entertainment and learning. And safety concerns were raised about privacy and vulnerabilities associated with increased use of and dependence on technology. Values for support and protection of the elderly were also short-term impacts requiring technological communication and facilitation of distribution of food and services that may have longerterm impacts.

\section{Environmental and Political/Regulatory Impacts}

As with technological and economic social systems categories, environmental and political/regulatory impacts will be addressed together even though the impacts were listed separately in the Bugeaud (2020) presentation. This will allow for a beginning across-social systems analysis that will become important in the next phase of the CLA where systems analyses explore commonalities and combined perspectives for emerging new paradigms, the third step in the CLA.

Shorter-term responses to the pandemic that may have partial long-term impacts as explored in the environmental category included living off the grid, relocation to rural communities and the increased planting of home gardens for fresh vegetables and to keep people out of stores. Longer-term responses included an increase in "do-it-yourself" (DIY) home improvements, work-from-home strategies with environmental impacts resulting from less travel, and work-home digital spaces that have less apparent but more negative impact on individuals' carbon footprints.

Increased use of drive-thru clinics and virtual healthcare were listed as having both environmental and regulatory impacts. The environmental impact on facilities use was perceived as both positive and negative 
as large-venue facilities were utilized during the pandemic for testing and vaccines and increased use of individual cars to receive these services had a short-term negative impact on the environment with increased idling and delivery of services and individuals to these venues or bringing services to homes via private transportation.

Safe internal spaces were examined to include wellness strategies to ensure better/safer air quality and use of more antimicrobial materials and coatings such as brass. Environmental analyses of air purification systems and the redesign of spaces to accommodate social distancing and reduce the spread of airborne viruses were expanded. Virtual workspaces were designed to create a sense of worker/avatar interactions for stay-at-home workers.

Developing increased DIY skills and voluntary emergent responses for things such as food distribution had regulatory implications that included stepping on the rights of contract workers for healthcare, utilizing and supporting right to repair laws to allow unlicensed expertise for home improvement, potential violation of existing health codes for food preparation and delivery, and encroaching on intellectual property rights as information was freely shared and distributed via the internet and intellectual property rights were relaxed to allow manufacturers to produce equipment to respond to the pandemic.

Legal services such as planning wills, virtual courts, and use of video conferencing in trials represented changes in regulatory systems that will likely have longer-term effects and become mainstream in our legal system. Questions about electronic voting and digital democracies were raised in the Bugeaud (2020) document even before the debacle of claims of voting fraud were made associated with the 2020 presidential election.

Political concerns raised during the pandemic included decisions to close boarders, limit international trade, restrict trade and consumer access to products, and address security vulnerabilities associated with increased use of technology. Decisions about limiting hate speech and spreading conspiracy theories were raised by the Bugeaud report several months before the attacks on the US Capitol in 2021 and the banning of President Trump on Facebook and Twitter.

\section{Value Shifts}

Like the technology category of social system responses to the coronavirus pandemic, many of the short- and long-term responses across categories have implicit implications for a shift in values. The values category of impacts in the Bugeaud study (2020) lists specific values shifts that emerged, many that were hinted at or exemplified in other categories as well.

For example, the values shift occurring with home-schooling where parents took on the role of teacher was stated specifically in the values category but suggested in other treatments of stay-at-home workers, demand for flexibility in work schedules, and work-life balance. Similarly, a shift in values towards cleanliness and personal hygiene was discussed in the values category but suggested in DIY creation of masks and sanitizer. Issues of availability and equity of healthcare services was also represented as a shifting value as free and universal healthcare became an increasingly noted value expressed.

One of the value shifts discussed was referred to as "sightseeing walks" where neighborhood walks and cycling increased during the pandemic, resulting in new-found appreciation and connectedness to "home" and community. Another value was for supporting local businesses, resulting in online purchases and patronage for carry out services from local businesses.

Another set of values includes increased value for autonomy and resourcefulness. This value was expressed as individuals developed new hobbies, designed and made their own masks, learned to give haircuts, or focused on their own mental and physical health. This value for increased autonomy was supported through internet accessibility which favored another shift or emphasis in valuing internet connectivity as a human right and recognition that not everyone had consistent and available online access.

Implied by many of the shifting values was an increased emphasis on nonformal learning and as-needed learning. Also with an implied shifting value for frugality, DIY strategies supported increased autonomy, feelings of safety and security, creativity, and self-care. Also evident in the early responses to the pandemic was a shift in value towards appreciating and recognizing appreciation for healthcare providers, home, and simple pleasures. 
On the negative side, there has been a shift in fear or suspicion of strangers, profiling, and confronting those who may exhibit different attitudes about safety, social distancing, or self-care. Concerns for personal safety and political divisiveness on the importance of vaccines were not apparent at the time of the publication of the Bugeaud study but became more apparent once the vaccines were released later that year.

\section{Arts and Culture}

Cultural shifts noted by the Bugeaud (2020) data included contactless ways of greeting one another, digital travel, virtual entertainment and museum experiences, and at-home entertainment. As discussed

previously, online concerts and benefits for fundraising involved innovative uses of technology and creative and artistic approaches to creating digital and virtual entertainment experiences and these trends are expected to continue or co-exist in the future.

Creative outlets through technology and to supplant isolation involved online cooperative gaming and sharing of expertise through YouTube, TikTok and other online venues. Increased pursuit of hobbies and development of new skills were enhanced by internet communications and nonformal learning. With more stay-at-home practices and experiences, there has also been a decrease in formal attire and a decrease in sales of business clothing.

\section{Summary of Litany Analysis}

The Litany phase of the CLA focused on short-term and long-term impacts of the coronavirus as presented in the Bugeaud (2020) data developed early during the pandemic. The data were summarized by their social systems categories and likely futures impact using content analysis.

In the next session, social causes and shared perspectives across social systems categories will be explored. The Systems Analysis phase of the CLA (Inayatullah, 2008) is a valuable futuring strategy for going deeper in analyzing social phenomena necessary for supporting transformational change efforts. This phase of the futuring process is especially helpful for further sensemaking of the Bugeaud data.

\section{Systems}

The System connections and relations analysis looked for common features across social systems categories. Attention was focused on values, policies, practices and trends that were reflected across the 141 trends and STEEPVAC categories generated shortly after the pandemic shutdown in April, 2020. Up to four key-word descriptors were assigned to each of the 141 trends to generate a list of 591 descriptors, with repetition. This first attempt to find emergent themes across the 141 trends was to present the summary of keywords identified in a wordcloud. The 591 descriptors were entered into the wordcloud software. Figure 6, below, provides a visual perspective of emerging themes conveyed by the litany of descriptions of the trends. Visual inspection of the wordcloud shows the emergence of key constructs including healthcare, entertainment, values, community, facilities, DIY, virtual, balance, safety, and learning. See Figure 6, below. 


\section{FIGURE 6 \\ WORDCLOUD OF SYSTEMS ANALYSIS OF KEY CONSTRUCTS}

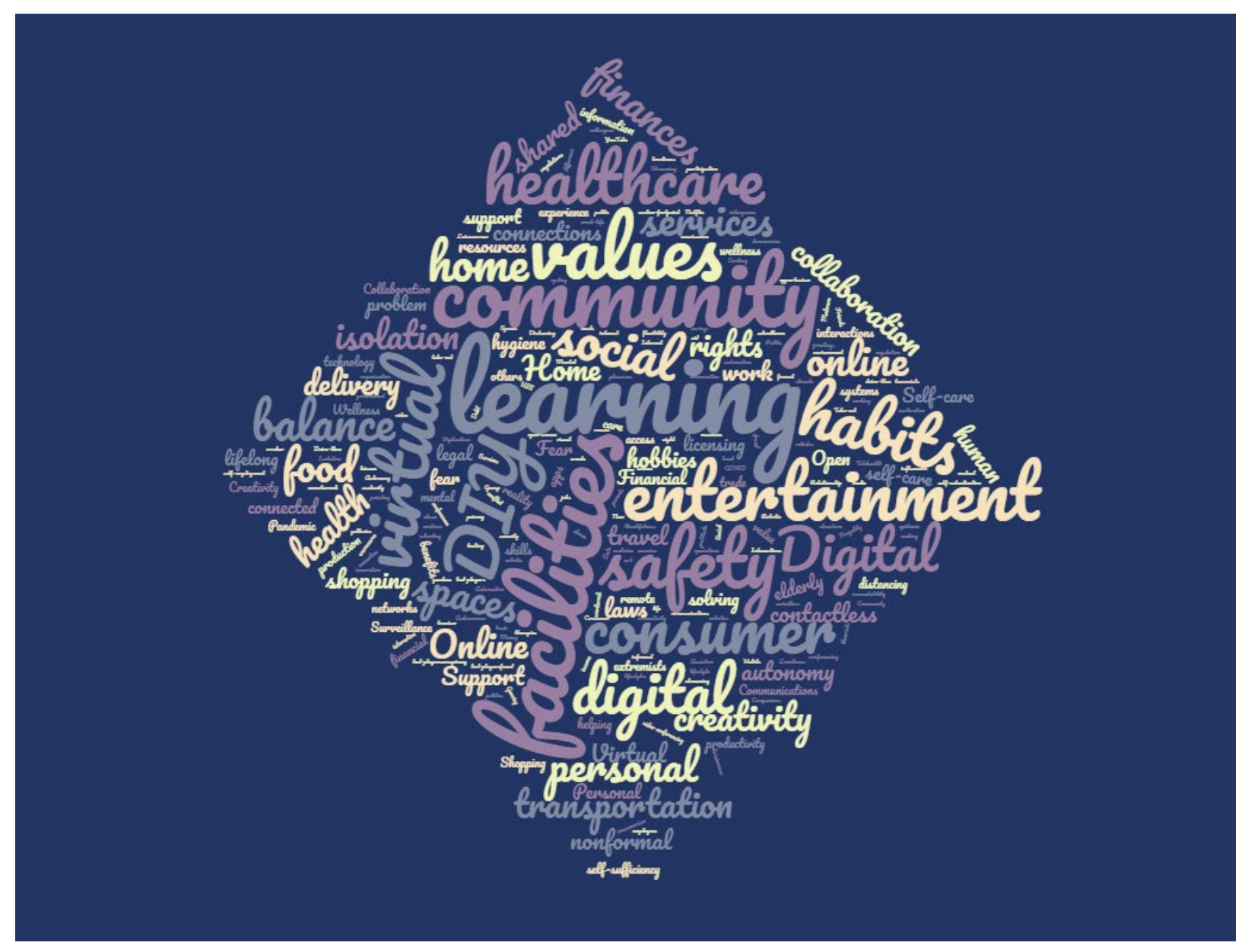

To create a more nuanced analysis, a second round of content analyses combined key constructs according to emergent themes. So, for example, "autonomy" was a descriptor identified in the first round of content analysis. Further examination of individual descriptors then included DIY, DIY problem solving, self-care, and self-sufficiency were re-categorized under the overall autonomy umbrella. Some themes such as collaboration were under-represented in the word cloud because the initial generation of constructs including items such as loneliness (2), networks (2), video-conferencing (2), and communications (3) which can be construed as aspects of collaboration from the context of the stated trends. So the 591 summary concepts were combined into over-arching themes, reducing the number of emergent themes to 24. Even with this combining of key constructs under umbrella terms, six of the 24 themes had fewer than 10 mentions so were not used for the next level of systems analysis. The chart below summarizes the 18 categories of themes with more than 10 citations in the content analysis. Items numbers indicate the number of items in the 141 descriptors that inferred this construct.

Space limitations prevent a full description of each of these 18 themes. The six themes with over 30 mentions will be described below. By focusing on categories with at least 30 mentions, descriptors occurring in at least $20 \%$ of the 141 trends will be represented. 
TABLE 1

RESULTS OF CONTENT ANALYSIS EMERGING CATEGORIES

\begin{tabular}{|l|l|}
\hline Themes/Implications & Items \\
\hline Autonomy & 28 \\
\hline Balance & $\mathbf{3 3}$ \\
\hline Collaboration & 16 \\
\hline Comforts & 23 \\
\hline Communications - Digital & 19 \\
\hline Community & $\mathbf{4 1}$ \\
\hline Consumer Services & 20 \\
\hline Distancing & 11 \\
\hline Entertainment & 18 \\
\hline Facilities & 27 \\
\hline Finances/Financial & 12 \\
\hline Habits & 11 \\
\hline Health & 20 \\
\hline Laws & 13 \\
\hline Learning & $\mathbf{6 5}$ \\
\hline Online & $\mathbf{3 4}$ \\
\hline Personal & $\mathbf{3 6}$ \\
\hline Values & $\mathbf{3 6}$ \\
\hline
\end{tabular}

Balance was a theme represented in 33 of the 141 trends. Balance was described in multiple ways as work-life balance, lifestyle, work-home spaces, remote-in person balance, technological use balance, and general balancing of life pressures. For example, item 29 states: The amount of time we're spending in front of a screen - whether for work, entertainment or as a means of staying connected - is directly leading to increases in screen time. Item 127 focuses on the challenges of home lifestyles: All of a sudden, every parent is a stay-at-home parent! And Item 123 conveys the challenges of lack of structure and the need for achieving a new sense of routines and balance: Our pre-COVID lifestyles followed a certain pattern. Now, there's an entirely new pattern at play: a lack of structure. Some are finding that creating daily routines helps cope with the lack of change in one's days.

Community was discussed in 41 of the trends in many different ways. In one sense, community was described as a renewed sense of place, as described in item 93: For many around the world, a walk around the neighbourhood has become a new form of sightseeing. It was also stated as a value with implied goals of supporting local business, for example in item 110: Fearing that many local shops will go out of business, customers are doing their best to support small businesses through online orders and gift cards. Several items conveyed the need to create or join new communities, such as item 52 which stated: As urban centres are seen as carrying higher risk of community transmission, many citizens are choosing to pack up and relocate to rural communities. Community was also conveyed as meeting the needs of clients in creating new communities, such as creating new digital "nightclubs" as described in items 5 and 7.

Learning was described in 65 of the items as acquiring new skills, creativity, teaching and learning, and DIY opportunities. Informal and nonformal learning were implied in many of the trends. For example, item 16: For many, COVID-19 lock-downs are creating the time for them to learn new skills they've been putting off. For others, they're turning to online tutorials to learn how to do things previously out-sourced (like giving haircuts) and item 24: As people are having to be more resourceful, many are turning to online sources like forums and YouTube for tips and advice for how to do things at home (cooking, baking bread, fixing dishwashers). Other learning examples included participating in virtual classes such as exercise classes, developing new computer skills, developing creativity outlets, acquiring new skills, learning how to complete tasks in new ways, such as online shopping, becoming their children's home-school teachers, 
developing new hobbies such as cooking and woodworking, and learning new computer apps that include virtual reality and assistive technologies. There were also items with implied learning needs such as the increase in scamming and conspiracy theories requiring new forms of vigilance and discernment. That almost half of the 141 trends had inferred learning components suggests the importance of lifelong learning as we transition during PPT.

The word "online" was mentioned or implied in 34 of the items and defined many of the experiences associated with trends during the pandemic. For example, several items referred to increased amounts of time online and the increased use of online platforms for socializing, sharing and competing, as described in item 9: In an effort to pass the time and stay socially engaged, viral challenges are being increasingly shared on social media. Other items referenced health and safety connections as online communications were used for information gathering as well as misused by those who were trying to scam people seeking information. Other items specified the use of online ordering for food, medicine, and shopping and accessing other online marketplaces, services and trading platforms. For example, item 41 described the use of digital pharmacies for online ordering: Digital pharmacies are using online ordering systems paired with delivery companies to deliver required medicines and drugs to people's homes. Online education was highlighted in several of the trends focused on online pandemic responses. Online instruction was mentioned from the perspective of accessing learning materials as well as collaboration, as summarized in item 17: We're seeing home-schooling being accelerated by the lockdowns. For many students, homeschooling means using technology to access online learning materials... Older students collaborate on online modules and online group projects. Online work was also described in several items, including the increased use of video-conferencing as described in item 4: We're seeing an uptick in the use of videoconferencing technologies to keep us connected with coworkers, family, friends and services. Increased use of and outlets for gambling and pornography were also described in several of the items describing online usage during the pandemic.

The 36 items categorized under "personal" referenced isolation, individual responses to the pandemic, personal spaces, personal support and personal safety. For example, contactless options for food delivery, limited social contact, isolation, and creation of personal home and electronic spaces signified shifts in how individuals interact with and navigate the world. For example, item 59 summarized: Perhaps one of the most important shifts that COVID-19 has brought about is our use of digital tools as makeshift spaces. With added development, the design of digital environments in which we work, play and socialize is nearing the horizon. Limiting human contact was also sited in several ways, including item 62: Limiting human contact has become a focal point of all, prompting new service models and products to reach the market. And personal safety and suspicion of others was described in item 126: An unjustified fear of strangers has manifested itself in certain communities, prompting racial profiling and racism to rise. In other cases, it's the misconception that those you know are "safe" and that strangers are the "others" that might be carrying the virus. This issue of personal safety and suspicion of the other has grown as mask and social distancing mandates are being lifted with larger proportions of our population now vaccinated.

Shifting values were also identified in 36 of the items. Shifting values include care for the elderly, appreciation for healthcare workers, opportunities to help others, and increased expectations that universal healthcare and universal basic income should be human rights for all. There were also several items referencing how isolation and social distancing increased values for connections, interactions, information, and shared experiences. Shifting values also included appreciation for what we have as well as adjusting to shortages resulting from disruption of distribution outlets and hording. As summarized by item 42: Closing borders and limiting international trade has restricted trade and consumer access to products, leaving many to make do with alternatives or learn to adjust to a life without such abundance. Increased desire to collaborate to solve social problems was also sited in several of the items as representing increased value for working together, such as item 14: Recognizing that we must act collaboratively to find solutions to the global pandemic, several organizations have launched open calls to innovators, creatives, and businesses... to increase effectiveness of communication strategies or look to build networks between disparate groups.

As described above, the systems level analysis of the 141 trends revealed 18 overarching categories of social systems responses to the pandemic in the early months of the pandemic. The CLA approach uses 
systems level insights to understand the discourse and dominate perspectives of a society or social system. A deeper examination of these insights reveals existing and emerging underlying metaphors and myths that become especially important when working for transformational change. In order to move an organization, policy, or society forward, these underlying myths and metaphors need to be exposed in order for new myths and metaphors to arise. The next section of the CLA analysis will be to examine the underlying myths and metaphors as revealed through the Litany and Systems analyses.

\section{Worldview}

The third level of CLA is Worldview (Inayatullah, 2008). As an approach to transformational futures, identifying underlying myths and metaphors becomes important before we can truly imagine a different, preferred future. To go deeper into the meanings of the discourse represented by the 141 strategies as summarized in the previous two analyses, an Integral Futures (IF) strategy (Slaughter, 2020) is used.

Sometimes referred to as a Four-Quadrant analysis, IF approaches integrate individual and social dimensions to understand complex interactions and reveal underlying perspectives that may prevent adaptive or transformational change from occurring. It is a strategy used by futurists to support transformational social change. Thus, IF is a form of critical futures that disrupts traditional ways of seeing and doing.

The Four-Quadrants of the IF approach are constructed using a 2x2 matrix where one dimension focuses on individual thoughts and actions and the other dimension conveys social or collective "thoughts" and actions. The figure below captures the Integral Futures framework.

\section{INTEGRAL FUTURES FRAMEWORK}

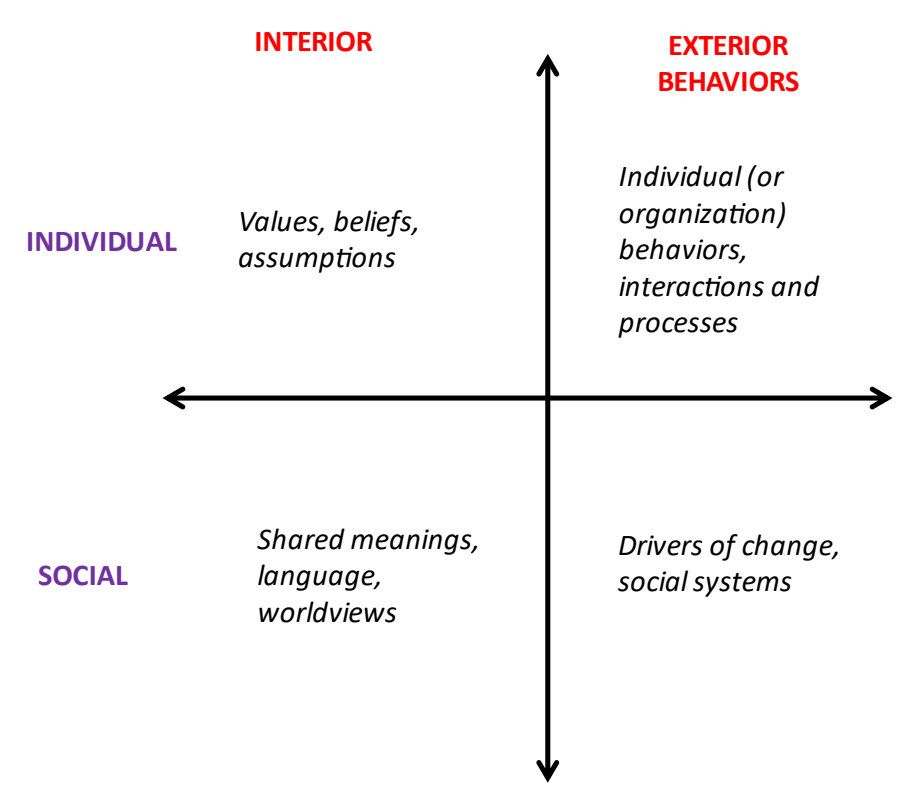

Adapted from Slaughter, 2020

Using the overarching categories explored in the systems-level analysis of post-pandemic responses, we can begin to see a post-pandemic worldview emerging. Figure 8, below, summarizes some of the findings of the systems analysis in the IF framework. 


\section{FIGURE 8 \\ WORLDVIEW IF ANALYSIS OF SYSTEMS-LEVEL FINDINGS}

\begin{tabular}{|c|c|c|}
\hline \multicolumn{2}{|c|}{ INTERIOR } & EXTERIOR \\
\hline INDIVIDUAL & $\begin{array}{l}\text { Autonomy, balance, } \\
\text { creativity, comforts, } \\
\text { community, } \\
\text { collaboration, health } \\
\text { (mental \& physical), } \\
\text { learning, self- } \\
\text { actualization, safety }\end{array}$ & $\begin{array}{l}\text { DIY, volunteerism, } \\
\text { demonstrations of } \\
\text { appreciation and } \\
\text { care, exercise, job- } \\
\text { life balance, family }\end{array}$ \\
\hline SOCIAL & $\begin{array}{l}\text { Helping others, } \\
\text { appreciation for others, } \\
\text { connection, social \& } \\
\text { economic services, } \\
\text { environment, } \\
\text { technology, } \\
\text { interconnections, } \\
\text { social/community } \\
\text { spaces, learning, } \\
\text { standard of living }\end{array}$ & $\begin{array}{l}\text { UBI, universal healthcare, } \\
\text { laws, public and social } \\
\text { spaces, community } \\
\text { activities, environmental } \\
\text { stewardship, social } \\
\text { services, opportunities, } \\
\text { human rights \& equal } \\
\text { justice }\end{array}$ \\
\hline
\end{tabular}

From an individual perspective, the drive for self-actualization with increased values for work-life balance, health, learning, safety and contributing to society (upper left quadrant) is actualized through volunteerism, DIY activities, formal, informal and nonformal learning engagements, exercise, family and community engagements, and volunteerism (upper right quadrant). At a social systems level, we see emerging values enacted at the social systems level (bottom right quadrant) through discussions of Universal Basic Income (UBI) and universal healthcare as a civil right, environmental stewardship and laws that protect individuals and the environment while supporting emerging consumer and self-employment needs, rearrangement of public and social spaces, and concern about equal access and opportunity.

The hardest quadrant to analyze is the social/internal (bottom left) quadrant. This quadrant conveys meaning systems, language, myths and stories that reveal social values (Inayatullah, 2008). From the Bugeaud (2020) data, social values and language centered on interconnectivity and values for social and community spaces to support individuals' safety, health and self-actualization needs. Values for learning and helping others were also evident as a social response to the pandemic.

From a CLA analysis, it is important to begin to recognize how social myths, metaphors, language, meanings, and sensemaking are changing. The Bugeaud data supports the idea that society is moving to more holistic, integrated, and sustainable perspectives. Even as shortages occurred due to trade disruptions, the perspectives at the social level emphasized creative solutions, small-group, local responses, and shifting laws to accommodate emergent business models and protect those who are under-employed and/or selfemployed. There were also suggestions that value was placed on many dimensions of contribution to society, not just individual accomplishment and wealth. The standard modern metaphor of the rugged individual was clearly NOT evident in the responses to the pandemic, suggesting a social movement away from the Horatio Alger view of success to a more collective, collaborative view of individual and social success.

The final stage of the CLA analysis extends the emerging worldview analysis to begin to shape the emerging societal metaphor as it surfaced during post-pandemic responses to provide the context for our discussion about the future of higher education. 


\section{New Myths}

The fourth level of the CLA explores new Myths as they are emerging and for which we can build toward preferred, desirable futures that are transformational. From the Integral Futures framework, the social metaphor and meaning systems observed from the post-pandemic responses and trends reveal a different view of individuals, their contribution to society, the role of society, and the values that will disrupt and serve to transition from modernism to post-normal times.

The views of the individual in this emerging social myth include the importance of self-actualization, lifelong learning, work-life balance, family and social connections, and opportunities to make a difference in society. Shifting values for basic rights that include the rights to minimum basic income and universal healthcare further support the social idea that individuals can and should contribute to society in a variety of ways and should be able to expect support from society regardless of income or social status. Although space limits did not allow in-depth analyses of some of the shifts in laws to accommodate post-pandemic responses discussed in the trends analysis, there were clear indications across several of the items that gatekeeping laws based on professional standards prevented self-employment and creative response that were important for local adaptive responses during the pandemic. Even health standards were called into question, supporting the need to examine and seek alternatives for production strategies and delivery of services. For example, food preparation and distribution strategies and creative approaches to developing PPE (Personal Protective Equipment) were important to the adaptive responses in the early stages of the pandemic.

The view of society represented in the post-pandemic response did not emphasize the importance of the "rugged individual" facing adversity independently but emphasized collective action for collaboration, cooperation, and lifelong learning. It also conveyed shifting ideas about identity, safety, individuality, the role of work and the importance of community. Technology was primarily at the service of this perspective of the self-actualizing, interconnected community, but also served as a mechanism for abuse and "badplayers" to take advantage of new learners and vulnerabilities.

\section{DISCUSSION}

Guiding questions for this study are: (1) What are the long-term stressors to higher education evident from the Coronavirus pandemic? (2) What are the possible, probable and preferrable futures for higher education? and (3) How can we address the challenges and embrace the opportunities of post-pandemic times to create more equitable, inclusive and sustainable higher educational futures?

The first question will be answered by considering the results of the CLA Level 1 Litany Analysis and the Level 2 Systems Analysis of the partial and sustained long-term responses to the pandemic as they impact higher education. Post-pandemic times are embedded within a Post-Normal framework that opens us to the need to transform society to accommodate radical changes resulting from the speed of change and shifting social structures.

The second question is addressed by considering the Level 3 and Level 4 worldview and mythical analyses. The second research question has an embedded assumption that higher education can serve as an impetus to societal transformative change which will be explored.

The third question will extend the response to question 2 to ensure changes in higher education that facilitate social transformation do so with an eye to social justice, inclusivity, and equality.

\section{Question 1: Stressors to Higher Education}

A combined social inquiry perspective of the stressors to higher education summarized through the Litany and Social Systems examination process reveal an emphasis on and needs to support selfactualization, societal contributions, lifelong learning, and appropriate and knowledgeable use of technology. Key themes include developing autonomy within the context of increased values for community and making a difference, supporting home-life-school balance and preparation for futures that allow expression of healthy lifestyles, ensuring safety and nurturing habits for caring and nurturing of others, providing opportunities for entertainment and social connections in safe environments, preparing 
students for an increased use and presence of technology, artificial intelligence, virtual reality and robotic interactions, and supporting society as it transitions through post-normal times.

Higher education was designed for a prior time period. The themes that emerged from the CLA analyses of post-pandemic social system responses, as listed above, suggest the following stressors to higher education that create pressures for change. These include the needs to:

- develop approaches to higher education that support lifelong learning, critical thinking and creativity,

- prepare students for multiple types of work environments including emerging types of work opportunities that they may play a part in developing,

- prepare students for self-employment and/or alternative ways of bringing value to society as well for serial employment,

- support development of collaboration and communication skills,

- use technology and discern information to support learning inside as well as outside formal learning settings,

- model renewable and sustainable practices including school-life balance, blended learning, and smart campuses,

- rethink credentialing, curriculum, and graduation expectations,

- rethink who may need higher education credentials,

- rethink facilities use and finances,

- eliminate a one-size-fits-all approach to education,

- extend higher education's reach to workplace and community learning as part of a core mission,

- develop educative experiences that support entrepreneurial and futures mindsets,

- rethink the purpose of higher education as preparation for work (especially in light of universal basic income and eliminating wealth gaps); and

- create fair and equitable opportunities for participation in higher education.

These recommendations may not appear as radical as they need to be in order to accommodate the post normal societal contexts. The biggest challenges to higher education may be the perceived relevance and contributions a college degree may offer to individuals and society. Especially traditional four-year institutions will need to struggle with their identity and purpose as their relevance and contributions are called into question. The rising costs of higher education and the challenges of student loan debt further place demands on higher education to rethink how to create meaningful learning environments without the high overhead costs and expectation that students pay for their education. If higher education continues to be perceived as a social good (which is not a given), the public will need to figure out different ways of supporting higher education and will likely then have more expectations and input into higher education operations. Many of our deeply held values of academic freedom and the tenure process will likewise be challenged and take on new forms.

The issues of credentialing, credit hours, core curriculum, entrance exams, and certifications may also need to be reconsidered along with the purpose of higher education. As a shift to support learning-to-learn skills is emphasized, knowledge as it has traditionally been defined and determined is called into question, especially with rapid changes of knowledge and ready access to information via technology. The question of what is most worth knowing if self-actualization and lifelong learning are goals challenges traditional curriculum sequencing, course checklists, curriculum standards, uniform testing, learning that occurs in 18week time frames and as measured by exams and distinguished by grades, and fragmented learning across classes and disciplines. Even in highly structured knowledge domains like mathematics or engineering, the emphasis that important understandings need to occur through separate content courses will be called into question and big-picture thinking will need to be developed.

Although the Bugeaud data was not focused on higher education and therefore did not address issues of higher education funding, increased safety requirements due to contagion, face-to-face and online learning concerns, and the conflicting needs for building community while supporting social distancing are specific, long-term issues higher education must face. As described above, challenges of student debt, the 
high costs of higher education, and waning public support for 4-year institutions will require rethinking service models, funding structures, personnel needs, and appropriate outcomes that support a value-added perception of higher education. Community colleges with missions to provide diverse opportunities for students at a lower cost are positioned to be more adaptive in the coming post-pandemic era where the value of higher education as it is currently constructed is called into question.

These stressors to higher education resulting from the analysis of the Bugeaud data suggest specific strategies and opportunities for possible and desirable futures of higher education. These possible futures of higher education are discussed as a response to research question number 2 below.

\section{Question 2: Possible Futures of Higher Education}

Although the goal of this paper is to convey positive and promising possibilities for creating adaptive and desirable futures for higher education and society, there is a collapse portion of this transformational scenario. While higher education has an opportunity to be transformed in ways that better meet the needs of a post-normal society, especially in response to post-pandemic challenges, large research institutions and small private universities may be the most vulnerable as the transformation is occurring and may not survive the process. While it seems inconceivable to many of us who have spent our careers in higher education that the huge university power houses (with highly competitive division I sports teams) may be at risk, the issues of sustainability and impact are beginning to surface as the public is less willing to provide large portions of their state budgets to maintain the high level of services and diversity of offerings that currently exist across and within institutions of higher education. Nor is the public likely to continue to condone passing those costs on to families and students, resulting in the challenges of high student loan debt ratios.

As the emerging metaphors for higher education take to heart issues of lifelong learning, pursuit and development of creativity and novelty, and participating in social ecosystems that are rapidly changing, what may be most important is facilitating learning-to-learn strategies and developing students who are equipped with the skills and dispositions needed to contribute to a rapidly changing society. As a new "social contract" emerges that supports citizen participation and contribution equally and eliminates the huge income disparities that currently exist in society, higher education can play a role in developing the entrepreneurial, creative, and caring habits of our students. New competencies and skills that include futures learning strategies and understandings (Bishop \& Hines, 2012; Miller, 2018) may need to be incorporated as central to the academic mission. Traditional content knowledge may then be pursued on an as-needed and as-interested basis while students are supported to engage in scholarly approaches to social problems that are trans-disciplinary.

Learning opportunities and contexts will need to be supported in both formal and informal settings, opening new opportunities for higher education to support society "beyond the walls" as part of core mission (verses as add-ons). Formal settings for higher education will include traditional educational settings, albeit, paired down with many likely closings of universities, as well as continued growth in virtual and community settings making the "place" of education more open and variable.

Brian Alexander's recent book Academia Next (2020) echoes these tensions and examines his own set of trends and data that convey a future of higher education that is going to be challenged. He, also, approaches the issue of the future of higher education from a systems perspective and recognizes that medium- to long-term predictions about the future of higher education are interwoven with the challenges of global warming, climate change, worldwide pandemics, political upheaval, economic systems, immigration, aging populations, technological innovations, as well as social systems factors. His trends analyses of demographic shifts as well as technological innovations are especially important for considering how higher education may play a role in the future to support intergenerational learning and the merging of artificial intelligence and adaptive learning and working strategies facilitated though virtual reality and robotics, even in the face of rapid changes and lack of ability to predict very far into the future.

The challenge we have with "unknown, unknowns" (Alexander, 2020, p. 213) is we can't predict them. These future surprises, disruptions, or trends that have nonlinear impacts cannot be predicted, but they can be accommodated. This is where the Futures Cone in Figure 1 reminds us how to set a course, even recognizing that changes and disruptions will occur as we continue on a transformative change journey. 
The further away from the present we get, the harder it is to create, today, the mechanisms and systems we may need in 15-20 years. The Expanded Now perspective of the futures cone informs our ability to have a broader perspective of the possible futures that we may engage and shape through our current actions. This is why it is so important to have guiding metaphors that support future decisions and actions to continue on a possible course that maintains a focus on the longer-term transformations we envision.

\section{Question 3: Creating a More Democratic Education System}

Through the CLA analyses, a guiding metaphor for the future is informed by the social systems perspective of mutual influences and impacts across STEEPVAC categories. To prepare higher education for meeting the challenges of the future in a post-pandemic, post-normal time, root metaphors will facilitate and inform decision making, structural changes, and sector-level understandings.

The CLA analysis led us to a view of the future guided by metaphors that embrace the complexity of the future, imploring both-and, parallel strategies (Smyre \& Richardson, 2016) that include both collective contribution and individual self-actualization, community connectedness and individual autonomy, and knowledge skills and futuring dispositions. I will use the metaphor of the nautilus to convey this emerging, dynamic, environmentally connected, living organism of a complex adaptive social system to understand our post-normal, post-pandemic world and our place in it (see Figure 9 below). Ultimately, of course, a guiding metaphor for a society emerges from ongoing social discourse. This is just my voice suggesting a perspective to show the power of how shifting and clarifying social metaphors could inform and shape social action and social transformation.

As a guiding metaphor, changes to higher education are shaped by the language and visions that are part of the metaphoric story of the future. The reason the rugged individual story worked so well in the United States was because individuals could easily translate that metaphor into every action and decisionmaking process. It also provided the basis for sensemaking and interpretation of action, for example, honoring the "self-made man." The nautilus, or any complex adaptive system, reflects dynamic, recursive, environmentally connected, emergent evolution. Rather than a linear projection, the nautilus shows a building on from where we are as a continuous process. Sometimes referred to as a "living fossil" (Teichert \& Matsumoto, 2010) history is evident in the present as the hard-shell past. Like the Expanded Futures Cone (Figure 1), meaning and understanding are continuously reexamined and open for reinterpretation by reconsidering the past, in the metaphoric sense, examining the rings of the shell of the nautilus as it grows. The nautilus is used in chaos mathematics as an example of recursive growth and dynamical interaction. It was also used as a metaphor for the soul by Oliver Wendell Holmes in his 1858 poem The Chambered Nautilus.

From the perspective of complex social systems, Figure 9 below superimposes the PNT and PPT perspectives onto the visual image of a nautilus. The hard-shelled portion of the nautilus are the infrastructure and guiding principles that support a society. At the very core of this metaphoric social system is social justice, equity and supports for the emerging society. Technology, safety, and care are also parts of the core as are environmental stewardship, and the creation and nurturing of public spaces. Virtual reality, artificial intelligence and robotics are emerging forms of technology that will shape continued viability of a PNT society. Values and goals of this metaphoric society appear in the growing part of the nautilus and serve as filters and guideposts for decision making, meaning making and action.

The value of any metaphor is in its use. As an example of how this metaphor could be used in decision making for higher education, we first connect possible and desirable future action to our core of social justice, equity, safety, environmental (both physical and social) stewardship, the creation of public spaces, support for collaboration and care, and using the most relevant technologies available, represented in white in the metaphoric nautilus. We keep an eye to the future and filter possible action through the environmental influences of robotics, virtual reality and artificial intelligence, represented in yellow, as we put in place decisions and actions that support key values and needs of our future, represented by the words in black in Figure 9. Each of these constructs emerged through the analysis of the Bugeaud data, depicting the emerging and long-term futures framing as unveiled through our social systems CLA analysis. (See figure 9 below.) 


\section{FIGURE 9 \\ ROOT METAPHOR FOR HIGHER EDUCATION FUTURES}

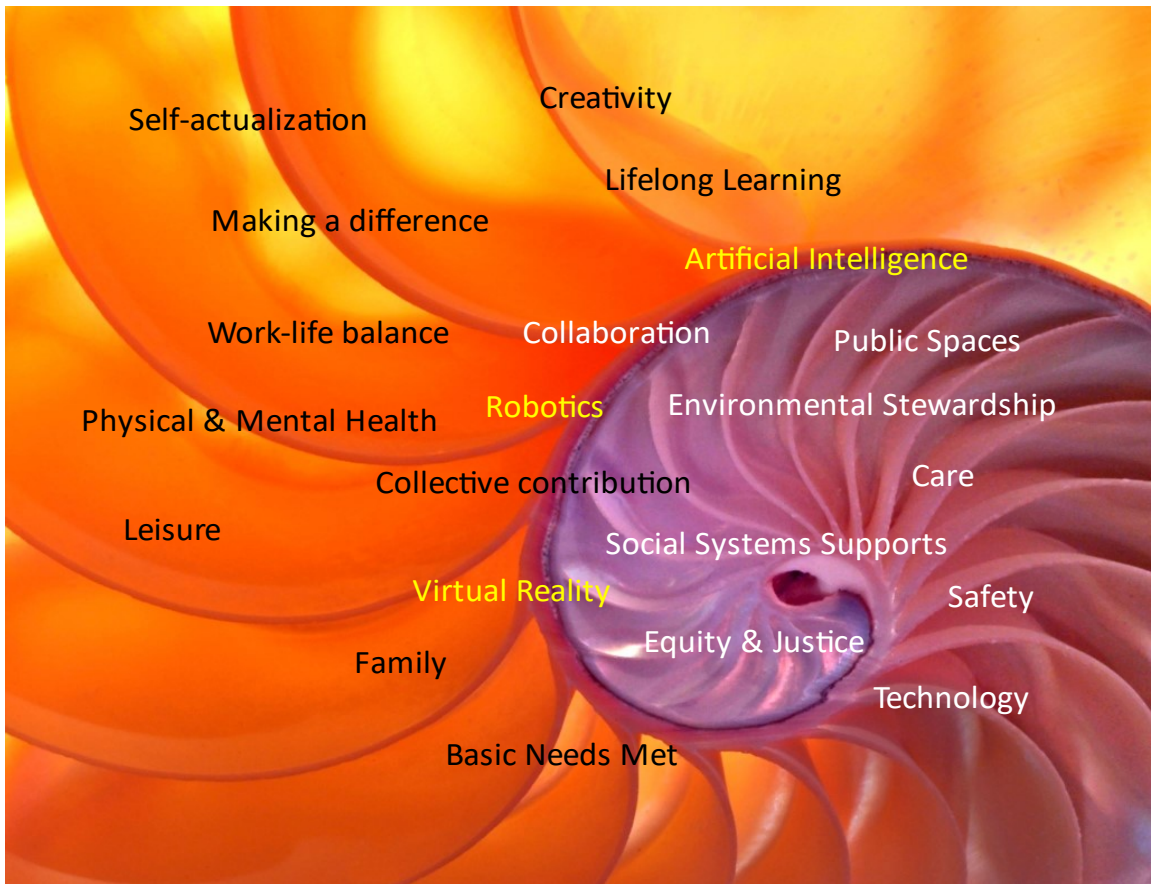

\section{CONCLUSION}

Our examination of post-pandemic responses and changes within the context of postnormal times provides the basis for an examination of thinking about the possible and desirable futures for higher education. While many of the specific insights gained from the social systems analysis suggested specific actions for response from institutions of higher education to adapt to these changing contexts, the Integral Futures analysis provided insights for a deeper, more sustainable framework through the examination and development of metaphors to guide action and shape the higher education discourse. Unlike many research studies that look to the past to make sense of the present and perhaps guide future action, this study used futuring strategies to explore and shape the discussion in terms of possible, plausible and desirable futures. This study is an example of how social systems inquiry and futures strategies can work together to provide new insights and opportunities for transformational change at a social systems level.

\section{REFERENCES}

Alexander, B. (2020). Academia next: The futures of higher education. Johns Hopkins University Press. Avenear. (n.d.). Retrieved from https://www.avenear.com/

Bezold, C. (2020). Aspirational futures. In R. Slaughter \& A. Hines, Knowledgebase of Futures Studies 2020 (pp. 143-156). Association of Professional Futurists (APF).

Bishop, P.C., \& Hines, A. (2012). Teaching about the Future. Palgrave Macmillan.

Bugeaud, R. (2020). A booklet listing 141 ways that the world has shifted in response to the pandemic. Avenear. Retrieved from https://www.avenear.com/covid-19-trends

Candy, S., \& Potter, C. (2019). Introduction to the Special Issue: Design and Futures (Vol. I). Journal of Futures Studies, 23(3), 1-2.

Coole, D.H., \& Frost, S. (2010). New materialisms: Ontology, agency, and politics. Durham, NC: Duke University Press.

CPNFS. (2021). Ignorance and uncertainty: Two key concepts that drive and shape our understanding and 
experience of PNT. Postnormal Times Essentials. Centre for Postnormal Policy and Futures

Studies (CPNFS). Retrieved from https://postnormaltim.es/essentials/ignorance-and-uncertainty

Dator, J. (2011). Futures studies. In W.S. Bainbridge (Ed.), Leadership in Science and Technology (pp.

32-40). Thousand Oaks, California: Sage Reference Series.

Dixon, D.F. (1984). Macromarketing: A social systems perspective. Journal of Macromarketing, 4(2), 417.

Fleener, M.J. (2016). Re-Searching methods in educational research: A transdisciplinary approach. In D. Stamovlasis \& M. Koopmans, Complex dynamical systems in education: Concepts, methods and applications (pp. 9-21). Berlin: Springer Publishing.

Fleener, M.J. (2021). Futures learning ecosystems (working title). (book under contract in preparation).

Fox, N.J., \& Alldred, P. (2015). New materialist social inquiry: Designs, methods and the researchassemblage. International Journal of Social Research Methodology, 18(4), 399-414. https://doiorg.prox.lib.ncsu.edu/10.1080/13645579.2014.921458

Funtowicz, S., \& Ravetz, J. (1993). Science for the post-normal age. Futures, 31(7), 735-755.

Greene, J.C. (2006). Toward a methodology of mixed methods social inquiry. Research in the Schools, 13(1), 93-99.

Greene, J.C. (2008, January). Is mixed methods social inquiry a distinctive methodology? Journal of Mixed Methods Research, 2(1), 7-22. Retrieved from http://citeseerx.ist.psu.edu/viewdoc/download?doi=10.1.1.579.3700\&rep=rep1\&type=pdf

Hines, A., \& Bishop, P. (2006). Thinking about the Future: Guidelines for Strategic Foresight. Washington, DC: Social Technologies.

Hines, A., Gary, J., Daheim, C., \& van der Laan, L. (2017). Building foresight capacity: Towards a Foresight Competency Model. World Futures Review, 9(3), 123-41.

Inayatullah, S. (1990). Deconstructing and reconstructing the future: Predictive, cultural and critical epistemologies. Futures, 22(2), 115-141. https://doi.org/10.1016/0016-3287(90)90077-U

Inayatullah, S. (2008). Six pillars: Futures thinking for transforming. Foresight, 10(1), 4-21. https://doi.org/10.1108/14636680810855991.

Kuhn, T. (1962/2012). The structure of scientific revolutions. University of Chicago press.

Luhmann, N. (1990). Technology, environment and social risk: A systems perspective. Industrial Crisis Quarterly, 4(3), 223-231.

Mendonça, S., Cunha, M., Kaivo-oja, J., \& Ruff, R. (2004). Wild cards, weak signals and organizational improvisation. Futures, 36, 201-218.

Miller, R. (Ed.). (2018). Transforming the future: Anticipation in the $21^{\text {st }}$ century. New York: Routledge.

Neuendorf, K.A., \& Kumar, A. (2016, January 4). Content analysis. In EDITORS, The International Encyclopedia of Political Communication. John Wiley \& Sons, Inc.

https://doi.org/10.1002/9781118541555.wbiepc065

Palese, E. (2013). Zygmunt Bauman. Individual and Society in the liquid modernity. SpringerPlus, $2(191)$.

Sadar, Z., \& Sweeney, J. (2016). The three tomorrows of postnormal times. Futures, 75, 1-13.

Sadar, Z., \& Sweeney, J. (2020). The three tomorrows of postnormal times. In R. Slaughter \& A. Hines, The knowledge base of futures studies 2020 (pp. 437-452).

Schilling, D.R. (2013, April 19). Knowledge doubling every 12 months, soon to be every 12 hours. Industry Tap. Retrieved from https://www.industrytap.com/knowledge-doubling-every-12months-soon-to-be-every-12-hours/3950

Slaughter, R.A. (2020). Integral futures: Theory, vision, practice. In R.A. Slaughter \& A. Hines (Eds.), The knowledge base of futures studies 2020 (pp. 237-257). Association of Professional Futurists.

Smyre, R., \& Richardson, N. (2016). Preparing for a world that doesn't exist-yet: Framing a second enlightenment to create communities of the future. John Hunt Publishing.

Teichert, C., \& Matsumoto, T. (2010). The Ancestry of the Genus Nautilus. In W.B. Saunders \& N.H. Landman (Eds.), Nautilus: The Biology and Paleobiology of a Living Fossil (pp. 25-32). Springer. doi:10.1007/978-90-481-3299-7_2 